\title{
NVC BASED MODEL FOR SELECTING EFFECTIVE REQUIREMENT ELICITATION TECHNIQUE
}

\author{
Md. Muqeem ${ }^{1}$, Dr. Md. Rizwan Beg ${ }^{2}$ \\ ${ }^{1}$ Research Scholar, Department of Computer Application, Integral University, Lucknow \\ 226026, India \\ muqeem.79@gmail.com \\ ${ }^{2}$ Professor \& Head, Department of CS\&E, Integral University, Lucknow 226026, India \\ rizwanbeg@gmail.com
}

\begin{abstract}
Requirement Engineering process starts from gathering of requirements i.e.; requirements elicitation. Requirements elicitation (RE) is the base building block for a software project and has very high impact on subsequent design and builds phases as well. Accurately capturing system requirements is the major factor in the failure of most of software projects. Due to the criticality and impact of this phase, it is very important to perform the requirements elicitation in no less than a perfect manner. One of the most difficult jobs for elicitor is to select appropriate technique for eliciting the requirement. Interviewing and Interacting stakeholder during Elicitation process is a communication intensive activity involves Verbal and Nonverbal communication (NVC). Elicitor should give emphasis to Non-verbal communication along with verbal communication so that requirements recorded more efficiently and effectively. In this paper we propose a model in which stakeholders are classified by observing non-verbal communication and use it as a base for elicitation technique selection. We also propose an efficient plan for requirements elicitation which intends to overcome on the constraints, faced by elicitor.
\end{abstract}

\section{Keywords}

Non-Verbal Communication, Elicitor, Stakeholder, Requirement Engineering.

\section{INTRODUCTION}

Requirements Engineering (RE) can be said as a group of activities which help us to find and communicate the need and purpose and context of system. RE process starts from gathering of requirements .i.e. requirements elicitation. Requirement elicitation is considered to be a very vital activity in requirement engineering. It is a proven fact that poor elicitation of requirements leads to a project failure. So for the improvement in the software industry's success rate more attention is required in the elicitation process. Elicitation is all about determining the needs of stakeholders and discovering what the user wants. It is one of the most critical activities in software development life cycle. The failure of the software projects has been concerns of the software industry from many years. Many surveys have been conducted to investigate the projects failure statistics. According to the Standish reports [1], success rate of software project is only $28 \%$. A major contributing factor in such a low rate of success is said to be unclear and imprecise requirements [1][2].In 2006 C. J. Davis et al discovered that "Accurately capturing system requirements is the major challenge in large software projects"[3]. To help overcome these problems we require an efficient approach for requirement elicitation. Success of the elicitation activity depends on the selection of appropriate technique. To above problems, formal RE methods and techniques were developed. Interacting Stakeholder is a communication intensive activity in which non verbal DOI : $10.5121 /$ ijsea.2012.3513 
communication plays an important role. In this paper we emphasize on Non Verbal Communication i.e. behavioral aspects, cues and signals [11], these aspects of non-verbal communication observed by the elicitor during interviewing and interacting stakeholders according to which during stakeholders are classified and use this as base for requirement elicitation technique selection

\section{PROBLEM DESCRIPTION AND SCOPE}

There is variety of elicitation techniques but it is considered a difficult task for an organization to decide which technique or combination of techniques is most suitable for the given stakeholders, organizational structure and project to be developed. This is normally because of lack of understanding about the available techniques. This inadequate understanding of elicitation technique leads to selection of improper elicitation technique for a given project, which ultimately can result in failure of the project. So, it can be very helpful for the requirement engineers to know about the selection of appropriate elicitation techniques [6]. The process of requirement elicitation has many difficulties to face and the most prominent is related with the communication between the stakeholders [7]. So it is again dependent upon the elicitation technique selected to improve communication between stakeholders. Requirement elicitors have a variety of elicitation techniques but flexible guidelines are required to be provided to them, which can be helpful for the selection criterion of elicitation technique [5].

\section{NON VERBAL COMMUNiCATION}

Nonverbal communication (NVC) [8], or body language, is a vital form of communication, a natural, unconscious language that broadcasts our true feelings and intentions in any given moment, and clues us in to the feelings and intentions of those around us. When we interact with others, we continuously give and receive wordless signals. All of our nonverbal behaviors, the gestures we make, the way we sit, how fast or how loud we talk, how close we stand, how much eye contact we make send strong messages. These messages don't stop when you stop speaking either. Even when we are silent, we are still communicating nonverbally. Oftentimes, what we say and what we communicate through body language are two totally different things. When faced with these mixed signals, the listener has to choose whether to believe your verbal or nonverbal communication, and in most cases we choose NVC. NVC, such as gestures, does hold potential as a source of additional user behavior data in a cross-cultural testing situation [7]. When such user data collection happens across different cultures, data is often collected and analyzed, ignoring the rich qualitative cues embedded in non-verbal communications such as gestures. In crosscultural situations, gestures can yield additional information from the user. NVC plays an important role while conducting interviews during Requirement Elicitation. Non -verbal behavior of the clients during Interview can be analyzed by the elicitor in order to record the requirement. If elicitor has ability to observe and documenting Non-verbal communication during interview as from the findings and suggestions given in this paper[11] the effective requirements may be recorded.

\section{Proposed Work}

Requirements elicitation is generally performed using an elicitation methodology or a series of techniques. Many such methodologies and techniques exist, all with the common aim to assist elicitor in understanding needs [9]. Although some elicitor think that just one methodology or just one technique is applicable to all situations, one methodology or technique cannot possibly be sufficient for all conditions [10]. Analysts select a particular elicitation technique for any combination of four reasons: (1) It is the only technique that the analyst knows, (2) It is the analyst's favorite technique for all situations, (3) The analyst is following some explicit methodology, and that methodology prescribes a particular technique at the current time, and (4) The analyst understands intuitively that the technique is effective in the current circumstance [8].It is well docu- 
mented from the discussion ,the present challenge during requirement elicitation is to select appropriate technique. Interacting Stakeholders during Requirement Elicitation, generally elicitors emphasize on verbal communication. The area of non-verbal communication (NVC) is still untouched .But when we observed. behavioral aspects, cues and signals of Non-Verbal communication like the use of facial expressions, eye contact, gestures, Tone of voice, body posture, orientation, touch, and various cues and signals such as distance, amused, sleepy, pitch, sound, pacing. NVC plays an important role while interviewing and interacting stakeholders during Requirement Elicitation. Non -verbal behavior of the stakeholder can be analyzed by the elicitor in order to record the requirement. If elicitor has ability to observe and documenting Non-verbal communication during stakeholders interaction effective requirements may be recorded [11].The major challenge of the elicitor is to record stakeholder's observation, classify the stakeholders accordingly and use this as base for selecting appropriate technique of elicitation so that effective requirements are elicited.

\section{REQUIREMENT ELICITATION TECHNIQUE SELECTION MODEL}

- Pre-Domain Analysis

- Stakeholders Identification

- Interviewing Stakeholder

- Classify Stakeholder

- Select Elicitation Technique.

- Eliciting the requirements.

Fig: 1 Stages of Proposed model.

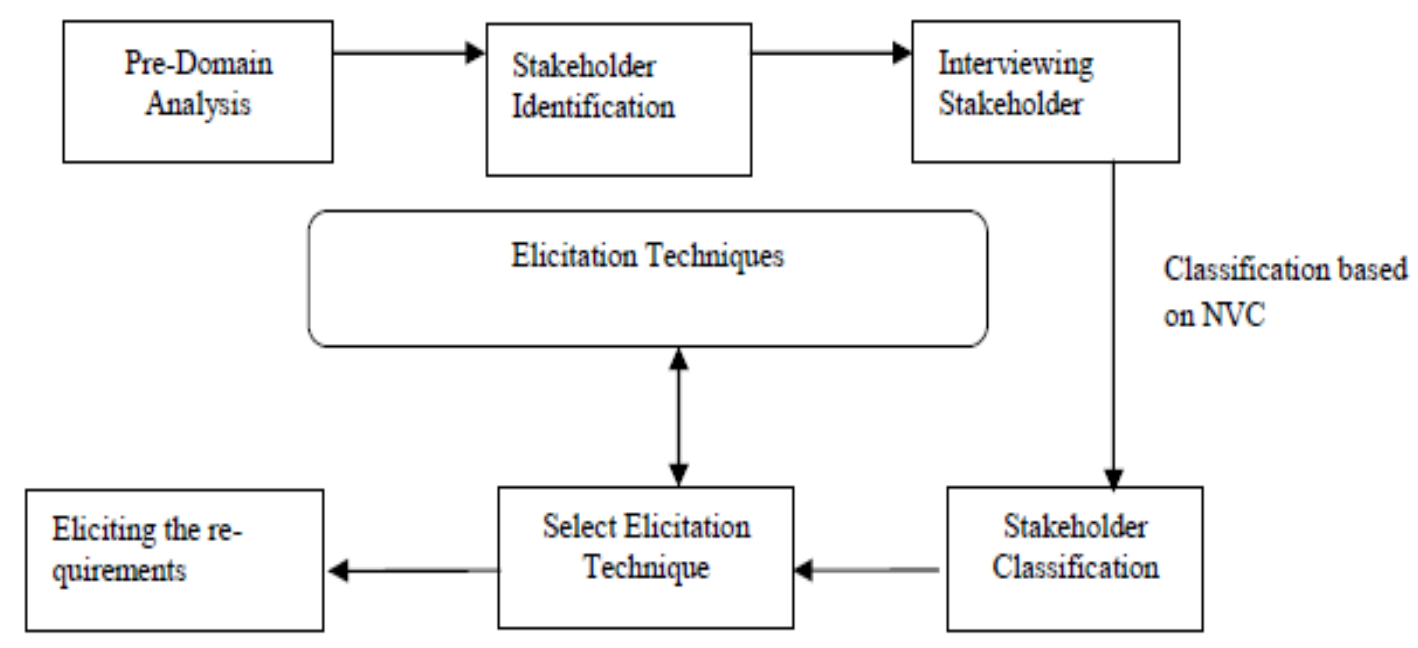

\subsection{Pre-Domain Analysis}

One of the most important goals of elicitation is to find out what problem needs to be solved and hence identify domain boundaries. These boundaries are defined, at a high level, where the final delivered system will fit into the current operational environment. Identifying and agreeing a system's boundaries affects all subsequent elicitation efforts. 


\subsection{STAKEHOLDERS IDENTIFICATION}

This step of stakeholder identification determines who your project stakeholders are, and their key groupings and sub-groupings. The primary aim of stakeholder identification is to name all those who could and should have a stake in a project.

\subsection{INTERVIEWING STAKEHOLDER}

In this step during Interview process elicitor interacts with stakeholders observes and document the needs of stakeholders. During stakeholder Interaction verbal as well as non-verbal communication is observed and recorded by the elicitor. The purpose of this step is to interact with stakeholders and classify them accordingly.

\subsection{Stakeholder Classification}

In this stage we classify stakeholders by observing NVC. In table 1 , we discuss various classifications of stakeholder situations and their effects during requirement elicitation. We can classify the stakeholders into three classes $(\mathrm{C} 1, \mathrm{C} 2, \mathrm{C} 3)$ by observing Non-Verbal communication [11] during stakeholder interaction.

1. Stakeholder is not aware about his own Requirements (C1).

2. Stakeholder Knows requirements but unable to express (C2).

3. Stakeholder knows his requirement but doesn't want to reveal it (C3).

The above three cases lead to poor requirement elicitation. To handle these issues we emphasize on Behavioral Aspects of Non-verbal communication and various cues, signals that are important in Non-verbal communication during stakeholder's interaction. During Interaction process of Requirement Elicitation, much of the non-verbal communication is exchanged using body movements and has up to 55\% impact. Certain behaviors can be better understood only through the interpretation of non-verbal cues with body movements being the only way of their communication. We have observed and recorded the behavior of these three types of Stakeholders .Accordingly we present our findings and suggestions in tabular fashion table $1 \&$ table 2 .

Table 1: Behavioral Aspects of Non-Verbal Communication [11] 
International Journal of Software Engineering \& Applications (IJSEA), Vol.3, No.5, September 2012

\begin{tabular}{|c|c|c|c|}
\hline $\begin{array}{l}\text { Behavior- } \\
\text { al Aspects }\end{array}$ & Case 1 & Case 2 & Case 3 \\
\hline Eye Contact & $\begin{array}{l}\text { - Widen eyes } \\
\text { - Look here and there } \\
\text { - Blank looks } \\
\text { - Eyes rolled upwards }\end{array}$ & $\begin{array}{l}\text { - Eyes moving all around } \\
\text { - Downward glances }\end{array}$ & $\begin{array}{l}\text { - Little eye contact } \\
\text { - Look somewhere else } \\
\text { - Glimpse from the corner of } \\
\text { their eye. } \\
\text { - Look down with shrugged } \\
\text { shoulders }\end{array}$ \\
\hline $\begin{array}{l}\text { Tone } \\
\text { Reaction }\end{array}$ & $\begin{array}{l}\text { - Speak in high voice } \\
\text { - Nervousness }\end{array}$ & $\begin{array}{l}\text { - Speak in low voice } \\
\text { - Unable to express him- } \\
\text { self }\end{array}$ & - Speak in monotonous tones \\
\hline Body posture & - Immobile & - Shrink to one side & $\begin{array}{l}\text { - May lean back indicate in- } \\
\text { difference lack of Interest. } \\
\text { - Hunch their back. } \\
\text { - Clench their fist. } \\
\text { - Show defensiveness. }\end{array}$ \\
\hline Gestures & $\begin{array}{l}\text { - Shrugs jerk up } \\
\text { shoulders to say no } \\
\text { in a response. }\end{array}$ & - Lot of hand gestures & $\begin{array}{l}\text { - Few hand \& arm move- } \\
\text { ments. } \\
\text { - Touch their face, throat, \& } \\
\text { mouth. } \\
\text { - Scratch their nose or ears. } \\
\text { - Touch their chest/heart with } \\
\text { open hands. }\end{array}$ \\
\hline
\end{tabular}


International Journal of Software Engineering \& Applications (IJSEA), Vol.3, No.5, September 2012

Table 1. Cues \& signals in Non-Verbal Communication [11]

\begin{tabular}{llll}
\hline CUES\& & CASE 1: & CASE 2: & CASE 3: \\
SIGNALS & & & \\
\hline Distance & Moderate & Low & High \\
Amused & High & Moderate & Low \\
Anxious & High & Moderate & Low \\
Confused & Moderate & High & Low \\
Sleepy & High & Low & Moderate \\
Crouching & Low & Moderate & High \\
Biting fingernails & Low & Moderate & High \\
Folding arms & Low & Moderate & High \\
Narrowing eyes & Low & Moderate & High \\
Voice Intensity & Low & Moderate & High \\
Pitch & High & Low & Moderate \\
Shaking & High & Moderate & Low \\
\hline
\end{tabular}

In order to record effective requirements we select different elicitation techniques according to stakeholder classification during stakeholder interaction.

\subsection{SeleCt Elicitation TEChNIQUe:}

- In Class 1 when requirements are not known by the stakeholder's (C1).Stakeholders are confused about their own requirements, provides unnecessary technical details rather than specify their requirements.

For $\mathrm{C} 1$ stakeholder should be made aware about his own requirements by counseling and providing domain knowledge .This can be done through interface prototyping", Brainstorming and "meeting discussion" elicitation technique.

- In Class 2 when Stakeholder knows requirements but unable to express (C2): In this case requirements are known by the stakeholders but unable to express it due to poor communication skills, domain terminology.

For C2 stakeholder should be motivated to express his requirement. Interview, workshops and group meeting are used as elicitation technique. When these techniques are used for eliciting the requirements effective requirements are elicited.

- In Class 3 when Stakeholder knows his requirement but doesn't want to reveal it (C3): In this case stakeholder aware about his requirement, he can express them but don't want to reveal 
International Journal of Software Engineering \& Applications (IJSEA), Vol.3, No.5, September 2012

them .This may be due to internal politics or the policy of the organization, fear .The factors led to poor requirement elicitation.

For C3 the matter could be reported to top management and fresh interviews should be conducted through Experts with different set of stakeholders. Expert Interviews, Questionnaires', Prototyping are best suited method for requirements elicitation in this situation.

Table: 3. Stakeholder classification and their effects

\begin{tabular}{|c|c|c|}
\hline Class & Effect in Elicitation & Elicitation Technique \\
\hline $\mathrm{C} 1$ & $\begin{array}{l}\text { Requirement is not } \\
\text { known by the stake- } \\
\text { holder. } \\
\text { - Provides Incomplete } \\
\text { requirement } \\
\text { - Provides unnecessary } \\
\text { Technical details. } \\
\text { - Incomplete domain } \\
\text { knowledge }\end{array}$ & $\begin{array}{l}\text { - } \\
\text { Interface prototyp- } \\
\text { ing } \\
\text { - Meeting Discus- } \\
\text { sion } \\
\text { - Brainstorming }\end{array}$ \\
\hline $\mathrm{C} 2$ & $\begin{array}{l}\text { Requirement is known } \\
\text { by the stakeholder. } \\
\text { - Stakeholder Unable to } \\
\text { express the require- } \\
\text { ment. } \\
\text { - Poor understanding of } \\
\text { Domain. } \\
\text { - Poor Communication } \\
\text { skill }\end{array}$ & $\begin{array}{ll}\text { - } & \text { Interview } \\
\text { - } & \text { Group Meetings } \\
\text { - } & \text { workshop }\end{array}$ \\
\hline $\mathrm{C} 3$ & $\begin{array}{l}\text { - Requirement are } \\
\text { known by the stake- } \\
\text { holder } \\
\text { - Stakeholder doest want } \\
\text { to reveal it. } \\
\text { - Requirements are not } \\
\text { shared with elictor }\end{array}$ & $\begin{array}{ll}\text { - } & \text { Questionnaires } \\
\text { - } & \text { Prototyping } \\
\text { - } & \text { Expert Interviews }\end{array}$ \\
\hline
\end{tabular}

\subsection{ELICITING THE REQUIREMENTS:}

Once the sources of requirements, specific stakeholders and their classification have been identified, the actual elicitation of the core requirements then begins using the selected elicitation techniques, approaches, and tools. During this activity it is important to establish the level of scope for the system and investigate in detail the needs and wants of the stakeholders, especially the users. If the elicitor follows the findings of the proposed work then requirements are elicited more effectively and efficiently. 


\section{EvAluATiON}

The software requirements elicitation comprises an early and critical but highly error-prone phase in software development. The purpose of surveys in requirements elicitation is to gather significant amount of data about the software product at the very beginning of the development process. In this paper we have elicited the software requirements of Web based Learning Repository. "Web based learning Repository " is a Web based portal that facilitates the students to search the learning material of engineering courses. In this case study we implement the proposed approach of requirement elicitation and apply all the steps.

a) In Pre-Domain analysis first we identify whether the project is existing and needs update or we are developing the project from scratch. After initial investigation we identify characteristics' of problem domain. These are usually static throughout the life of a project.

b) Identify Characteristics of the solution domain: These are likely to change whenever a new type of solution to the problem is proposed.

c) Identify Characteristics of the project: These are likely to change whenever culture or management changes.

d) Identification of key stakeholders: The users, the customers, the developers are identified. In our case study we target engineering students as users.

e) After identification of key stakeholders we start interacting with the key stakeholder's i.e. target focus groups and the client for whom we are developing the software.

f) During stakeholders interaction we record verbal communication and observe non verbal communication i.e. various cues signals and behavioral aspects. We can easily identify whether the stakeholders stakeholder is not aware of its requirements, unable to express it or doesn't want to reveal it. Once identified as case1, case 2, case3 we can take appropriate actions.

g) For case 1 stakeholder should be made aware about his own requirements by counseling and providing domain knowledge .For case 2 stakeholder should be motivated to express his requirement by providing prototypes, front end visuals etc. For case 3 the matter could be reported to top management and fresh interviews should be conducted with different set of stakeholders.

h) Start eliciting the requirements from the stakeholders by appropriate elicitation technique.

\section{GUIDELINES FOR EFFECTIVE REQUIREMENT ELICITATION}

- Assess Project Situation

- Identify Problem Domain characteristics

- Identify Solution Domain characteristics

- Identify Project Domain characteristics

- Identify Key stakeholders

- Observe and record Non-Verbal Communication during stakeholders interaction

- Classify stakeholders

- Select appropriate elicitation technique based on stakeholders classification

- Elicit the requirement

- Assess the elicited requirement

- Identify Conflict requirements

- Identify Ambiguous requirements 
- Prioritize the Requirements

- Plan for Risk management

\section{Conclusions}

There is variety of elicitation techniques but it is considered a difficult task for an organization to decide which technique or combination of techniques is most suitable for the given stakeholders, organizational structure and project to be developed. In this paper we propose an effective model for requirement elicitation technique selection. In this model stakeholders are classified by observing non-verbal communication and use it as a base for elicitation technique selection. We also propose an efficient plan for requirements elicitation which intends to overcome on the constraints, faced by elicitor. If the elicitor follows the findings of the proposed model effective requirements are elicited.

\section{ACKNOWLEDGMENTS}

First and foremost, our sincere thanks goes to Prof. Syed Wasim Akhtar, Honorable Vice Chancellor, Integral University, Lucknow. Prof Akhtar has given us unconditional support in many aspects, which enabled us to work on the exciting and challenging field of Software Engineering. We would also like to give our special thanks to Prof. T. Usmani, Pro Vice Chancellor, Integral University. His encouragement, help, and care were remarkable during the past few years. We are also grateful to Prof S. M. Iqbal Chief Academic Consultant, Integral University. Prof Iqbal provided us with valuable thoughts for our research work. My gratitude also goes to Dr. Irfan Ali Khan, Registrar, Integral University for his constructive comments and shared experience.

\section{REFERENCES}

[1] Standish Group, The CHAOS Report, http://www.standishgroup.com/sample_research/PDFpages/chaos1994.pdf.2005.

[2] Md. Rizwan Beg, Dr. Qamar Abbas, Ravi Prakash Verma, Analysis of various studies showing the impact of the requirements engineering on software project success, 2008.

[3] A. Davis, O. Dieste, A. Hickey, N. Jurist, and A.M.Moreno, Effectiveness of requirements elicitation techniques: Empirical results derived from a systematic review, In Proceedings of the 14th IEEE International Requirements Engineering Conference, 2006, pp. 176 - 185.

[4] Christel, Michael G.; \& Kang, Kyo C, Issues in Requirements Elicitation (CMU/SEI-92-TR-12). Pitts burgh, PA: Software Engineering Institute, Camegie Mellon University, September, 1992.

[5] Sarah Powell, Frank Keenan, Kevin McDaid, Enhancing Agile Requirements Elicitation With Personas ,IADIS International Journal on Computer Science and Information Systems, Vol. 2, No. 1, pp. 82-95, ISSN: 1646-3692.

[6] Zheying Zhang, Effective Requirements Development - A Comparison of Requirements Elicita-tion techniques, SQM2007 conference.

[7] Gabriela N. Aranda1, Aurora Vizcaíno2, Alejandra Cechich1, Mario Piattini2, Strategies to Minimize Problems in Global Requirements Elicitation, CLEI ELECTRONIC JOURNAL, VOLUME 11, NUMBER 1, PAPER 3, JUNE 2008.

[8] Ann M. Hickey, Alan M. Davis, Requirements Elicitation and Elicitation Technique Selection: A Model for Two Knowledge-Intensive Software Development Processes, Proceedings of the 36th Hawaii International Conference on System Sciences (HICSS'03), 2002.

[9] Macaulay, L., Requirements Engineering, Springer, 1996.

[10] Maiden, N., and G. Rugg, ACRE: Selecting Methods for Requirements Acquisition, Software Engineering Journal, 11, 5(May, 1996), pp. 183-192.

[11] Dr. Md. Rizwan Beg, Md. Muqeem, Md .Faizan Farooqui, Extending Application of Non-Verbal Communication to Effective Requirement Elicitation, ACITY 2012 